\title{
Experimental Research into the Mechanical Behaviour of Dammar and Sandarac - Based Bio Resins
}

\author{
DUMITRU BOLCU ${ }^{1}$, MARIUS MARINEL STANESCU2*, ION CIUCA ${ }^{3}$, ALIN DINITA4, ADRIAN ROSCA ${ }^{5}$, DANIELA ROSCA \\ ${ }^{1}$ University of Craiova, Department of Mechanics, 165 Calea Bucuresti, 200620, Craiova, Romania. \\ ${ }^{2}$ University of Craiova, Department of Applied Mathematics, 13 A.I. Cuza, 200396, Craiova, Romania \\ ${ }^{3}$ University Politehnica Bucuresti, Faculty of Material Science and Engineering, 313 Splaiul Independentei, 060042, Bucharest, \\ Romania \\ 4Petrolium-Gas University of Ploiesti, Faculty of Mechanical and Electrical Engineering, 39 Bucuresti Blvd., 100680, Ploiesti, \\ Romania \\ 5University of Craiova, Faculty of Agriculture and Horticulture, 19 Libertatii Str., 200421, Craiova, Romania \\ 6University of Craiova, Faculty of Electrical Engineering, 107 Decebal Blvd., 200440, Craiova, Romania
}

\begin{abstract}
In this paper, we examine two types of Dammar-based bio resins. In the first type, Dammar alone is used as natural resin, while in the second type a mixture of 70\% Dammar and 30\% Sandarac is used. Three sample sets were made of each of these resins with a bio resin volume proportion of 55,65 and $75 \%$ respectively, the rest being epoxy resin (used, together with the associated reinforcing material, to generate a quick polymerization process). A SEM analysis is carried out and the surface roughness of each of the studied materials. A series of mechanical properties, determined by tensile testing, are presented. We have determined the characteristic curves, tensile strength and modulus of elasticity and the influence of the epoxy resin volume proportion on the mechanical behaviour of bio resins.
\end{abstract}

Keywords: bio resin, mechanical properties, roughness

In the last decades great attention has been paid to composite materials, the components of which, whether matrix or reinforcing material, come from nature. The main advantages of using green composites are given by the fact that both the fibers and the bio resins are abundantly produced by nature, consequently they have a low cost of manufacture compared to synthetic composites. Moreover, they are totally biodegradable and have relatively good mechanical properties. Most composite materials that have been studied so far have focused on natural fibers as reinforcing materials, only in combinations with thermoplastic matrix (polypropylene, polyethylene and vinyl polychloride) or with a thermo-rigid (phenolic, epoxy and polyester resins) (see example [1]). Synthetic resins have the disadvantage of a processing limit due to the high viscosity at meltdown, phenomenon appearing when cast by injection, and the final product is hard to recycle. This disadvantage may be eliminated by using biological thermo-rigid matrices based on vegetable-oil resins since the latter are bio-degradable and, therefore, the polymerization process is not necessary [2-4]. Bio resins are resins derived from a biological source and, consequently, can be biodegradable and compostable, thus, hypothetically, they can decomposed after use. Natural resins can be fossil (amber), vegetable (Sandarac, Copal, Dammar), or animal Shellac). Natural resins are insoluble in water, however, they are slightly soluble in oil, slightly soluble in oil, alcohol and, partly, in petrol. They form solutions with certain organic solvents, solutions that can be used as covering lacquers. Turpentine, colophony, mastic is products resulted from the distillation of conifer resins. A study concerning the chemical composition of the properties of these resins is carried out in [5], and the applications are shown in [6] .

The studies conducted on these resins have focused mainly on their chemical composition and their chemical properties and less on their mechanical properties. Thus, work [7] was intended to broaden the knowledge about microbiological biodegradation of the lacquers based on Dammar in works of art subject to unsuitable protection conditions, particularly to long exposures to relative humidity. In [8] a new binder is introduced, modified from silicon and Dammar, which can reduce the use of the synthetic binder and which has improved, especially ecological, properties. The optimal composition of this binder, which ensures the best properties for impact, hardness, traction and adherence stresses, was determined. The way in which Dammar addition contributed to improve the rigidity, the modulus of elasticity and the hardness of modified silicon was studied in the work [9].

In [10] the Dammar gum is examined as supplementary material used for improving thermal conductivity and performance in preparing the material for changing the composite phase, while the possibility of using bee wax, tallow and Dammar as PCM (phase change materials) in concrete buildings is investigated in [11]. The effect of polymethyl-methacrylate (PMMA) on Dammar's physical properties for the application of covering lacquers was analysed in [12].

A model with free particles used for numerical simulation of charpy impact test of plastic materials is studied in [13].

Sandarac is presented in [14], as well as its uses and chemical composition in comparison with other very similar resins. An identification of Sandarac's main chemical components is performed in [15] and in [16] there is a qualitative and quantitative study on some Sandarac resin types with different origins.

The Young modulus for composite material constituent was obtained based on numerical analysis [17].

Still, there are not enough studies on the mechanical behaviour of natural resins. The mechanical characteristics (the tensile strength, percentage elongation and Young's modulus), the characteristics of water vapour transmission and the characteristics of moisture absorption of Dammar 
films containing softening agent were studied in the work [18]. The reaction to the compression stress of palm tree trunk treated with different amounts of Dammar resin was analysed in [19]. There are also few studies concerning composites with both their matrix and reinforcing material made of natural material. The mechanical behaviour of some composite materials with a bio resin matrix based on Dammar and with reinforcement made with cotton, flax, silk and hemp fabric is studied in [20] and [21].

\section{Experimental part}

To make the studied materials we used natural resins, namely Dammar and Sandarac. The first type of material was made by dissolving Dammar by turpentine. For the second type we dissolved a mixture of $70 \%$ Dammar and $30 \%$ Sandarac by turpentine too. We cast three plates of each these resins where the volume proportion of natural resin was $55,65,75 \%$ respectively. The difference up to $100 \%$ was made of Resoltech 1050-type epoxy resin together with its associated reinforcing material because natural resins dissolved in turpentine have a very long hardening time and the synthetic component generates points of quick activation of the polymerization process. We also made a specified epoxy resin plate, necessary for assessing the way in which natural resins influence mechanical behaviour. We made three sets of samples of the cast plates, which were submitted to experimental determinations. We will use the following symbols:

- DA 55- resin with a 55\% volume Dammar proportion;

- DA 65- resin with a 65\% Dammar volume proportion;

- DA 75- resin with a 75\% Dammar volume proportion;

- DS55- resin with a 55\% volume proportion of a mixture, composed of $70 \%$ Dammar and $30 \%$ Sandarac;

- DS 65- resin with a $65 \%$ volume proportion made of a mixture of $70 \%$ Dammar and $30 \%$ Sandarac;
- DS 75- resin with a 75\% proportion made of a mixture of $70 \%$ Dammar and $30 \%$ Sandarac.

Samples of each of the materials mentioned above here submitted to a SEM analysis that was performed by an electron microscope - Hitachi model S3400N/type II, having the following specifications:

-SE image resolution: minimum $3 \mathrm{~nm}$ at $3 \mathrm{kV}$ (100.000X, $W D=5 \mathrm{~mm}$, high vacuum mode);

-BSE image resolution: minimum $4.0 \mathrm{~nm}$ at $30 \mathrm{kV}$ (60.000X, WD $=5 \mathrm{~mm}$, low vacuum mode);

-Magnification Range: $5 x$ to $300.000 x$;

-Accelerating Voltage: $0.3 \mathrm{kV}$ to $30 \mathrm{kV}$.

As for the presented materials we measured the roughness of the representative samples. In order to do this we used a portable profilometer (Taylor Hobson Surtronic 3+) in which the analysed length varied between $0.25 \mathrm{~mm}$ and $25.4 \mathrm{~mm}$, with a sensor speed of $1 \mathrm{~mm} / \mathrm{s}$ (fig.1).

The examined samples underwent a tensile test, which was carried out according to the ASTM D3019 and ISO 527-4:1997 provisions. The elements obtained from this trial were: the characteristic curve, tensile strength $R_{m}$ [MPa], percentage elongation after fracture $A[\%]$ and elasticity modulus $E[\mathrm{MPa}]$. We used the LRX Plus testing machine from LLOYD Instruments with the following specifications:

- Force range: $2.5 \mathrm{kN}$;

- Travel: 1 to $735 \mathrm{~mm}$;

- Crosshead speed: 0.1 to $500 \mathrm{~mm} / \mathrm{min}$;

- Analysis software: NEXYGEN.

\section{Results and discussions}

Figure 2 shows images obtained on the basis of the SEM analysis of the epoxy resin (fig. 2.1), the bio resin made of Dammar only (fig. 2.2) and the bio resin with $70 \%$ Dammar and $30 \%$ Sandarac (fig. 2.3).
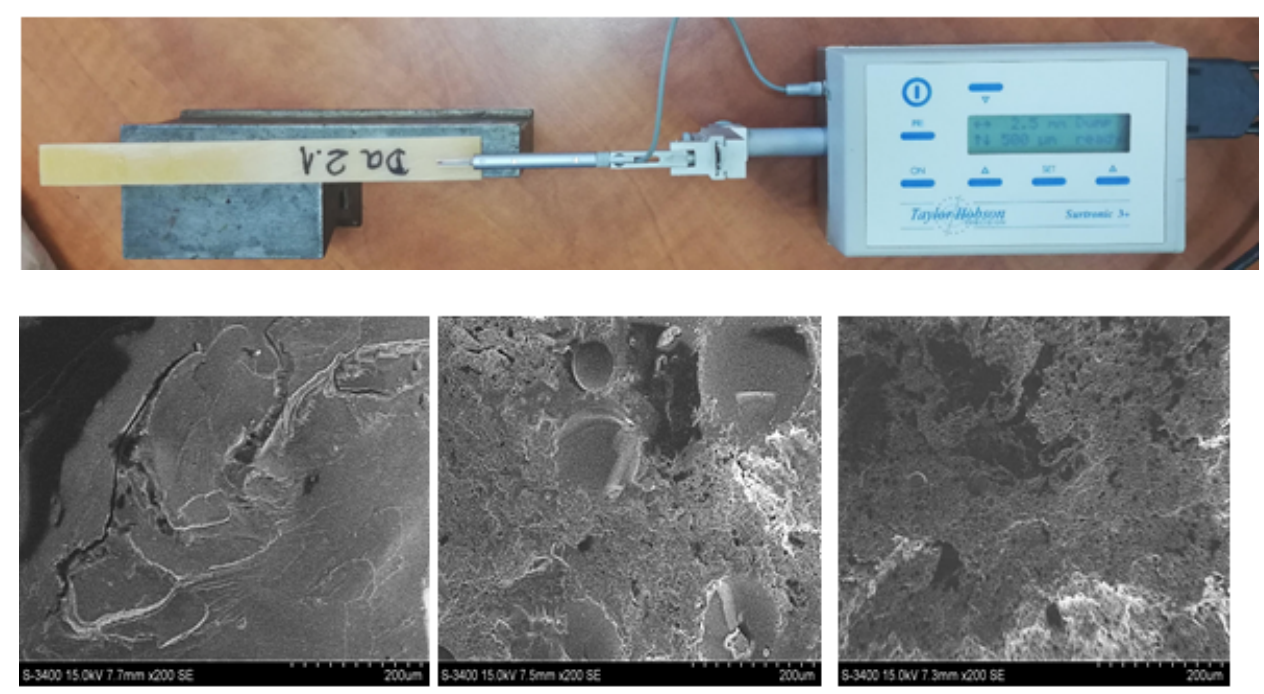

2.1

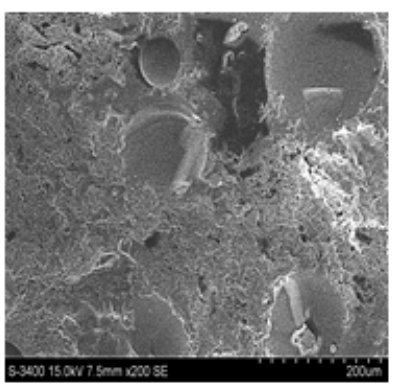

2.2

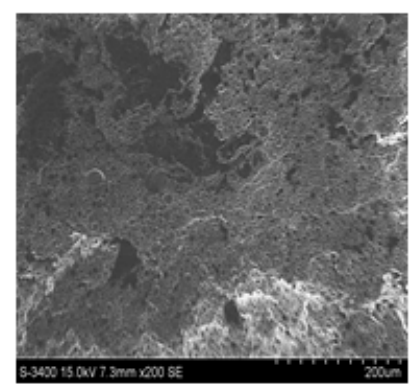

2.3
Fig. 1. Portable profilometer (Taylor Hobson Surtronic 3+)

Fig.2. Images obtained by SEM analysis of the three resin types

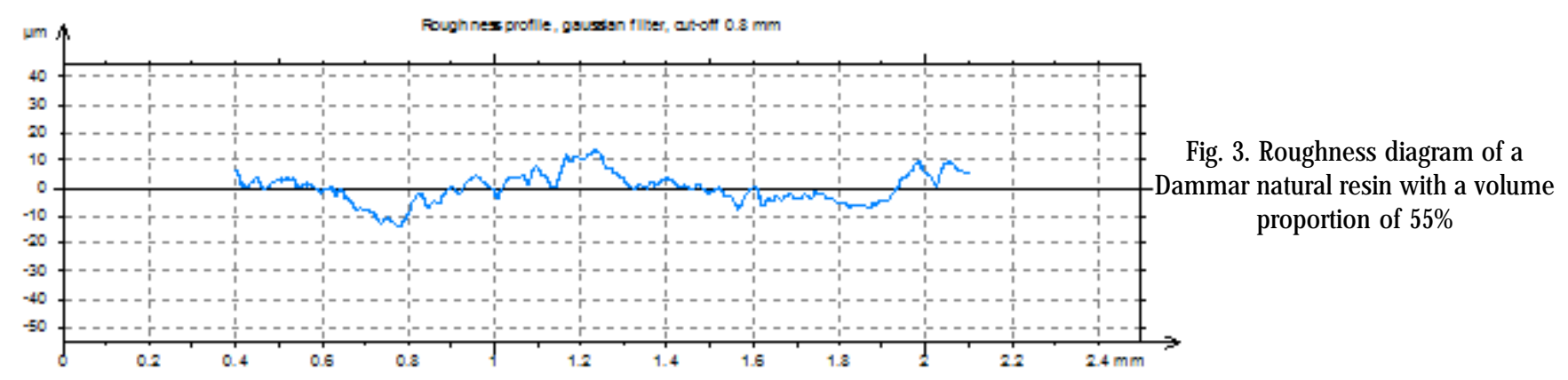


We can see that in the case of the bio resins there is a significant amount of air pockets. This can be explained by the fact that the polymerization takes place more slowly, the hardening of the resin takes a longer time and it is no longer possible to eliminate the air pockets.

In figure 3 we show the roughness diagram obtained for a Dammar natural resin with a volume proportion of $55 \%$.

Table 1 presents the results of the arithmetic mean deviation of the evaluated profile $R a$, in im (the arithmetic mean of the profile absolute values of the profile ordinates), of the studied materials.

\section{Table 1}

THE ARITHMETIC MEAN DEVIATION OF THE EVALUATED PROFILE $\mathrm{Ra}$, in $\mu \mathrm{m}$

\begin{tabular}{|l|c|}
\hline Resin type & $\begin{array}{c}\text { The arithmetic mean deviation of the } \\
\text { evaluated profile } R a[\mu \mathrm{m}]\end{array}$ \\
\hline DA 55 & 3.38 \\
\hline DA 65 & 2.84 \\
\hline DA 75 & 2.48 \\
\hline DS 55 & 1.94 \\
\hline DS 65 & 2.12 \\
\hline DS 75 & 1.42 \\
\hline epoxy & 1.76 \\
\hline
\end{tabular}

We observe an increase in porosity, compared with the epoxy resin, for all the samples containing natural resin. An explanation may be the polymerization time necessary for resin hardening. Thus, in the case of the epoxy resin the hardener produces a quick reaction, the air pockets being eliminated shortly, before the complete hardening of the resin, which happened in less than $24 \mathrm{~h}$. In the case of the mixtures of synthetic and natural resins the reaction time is longer, the hardening taking place in $72-96 \mathrm{~h}$. Since the reaction is longer, the viscosity has gradually increased until complete hardening. We can see an increase in the surface roughness of the natural resin plates in comparison with the plate obtained from epoxy resin.

Henceforward, by representative sample of a set we understand the sample with the medium values of the studied mechanical properties.

The characteristic curves of each representative sample of the three sets made of Dammar-based resin are shown in figures $4-6$.

Figures 7 - 9 show the characteristic curves of one representative sample of each of the three sets, made on the basis of the mixture of $70 \%$ Dammar and 30\% Sandarac.

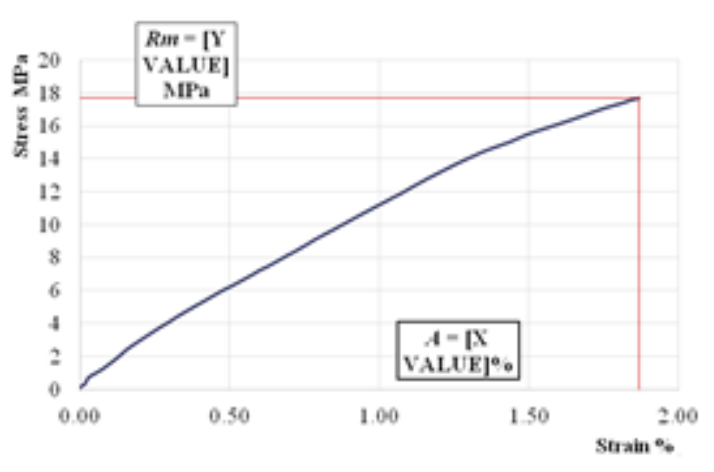

Fig. 4. Characteristic curve of DA 55 resin sample

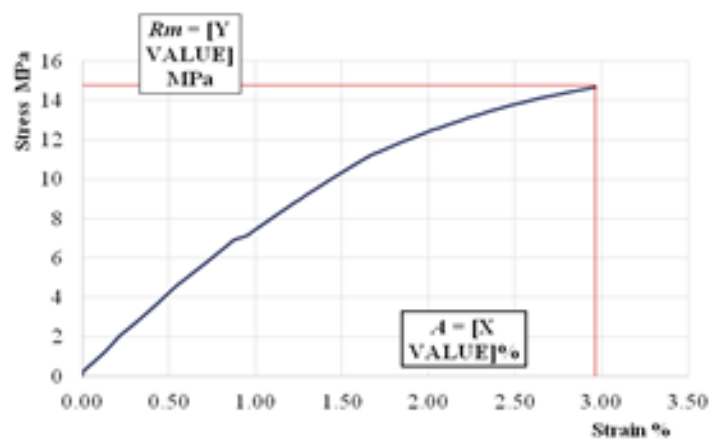

Fig. 5. Characteristic curve of DA 65 resin sample

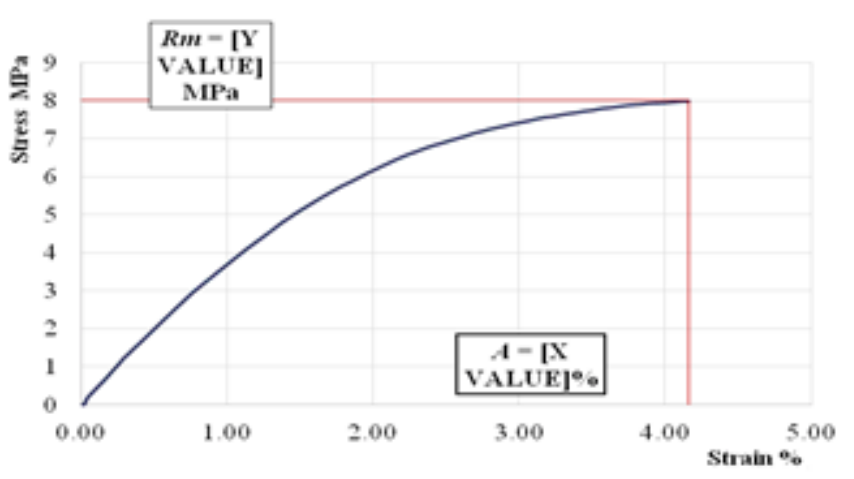

Fig. 6. Characteristic curve of DA 75 resin sample

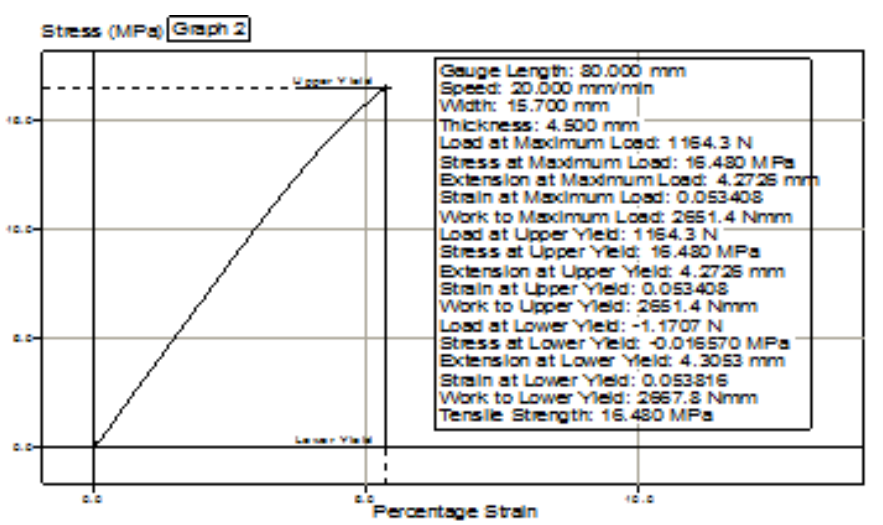

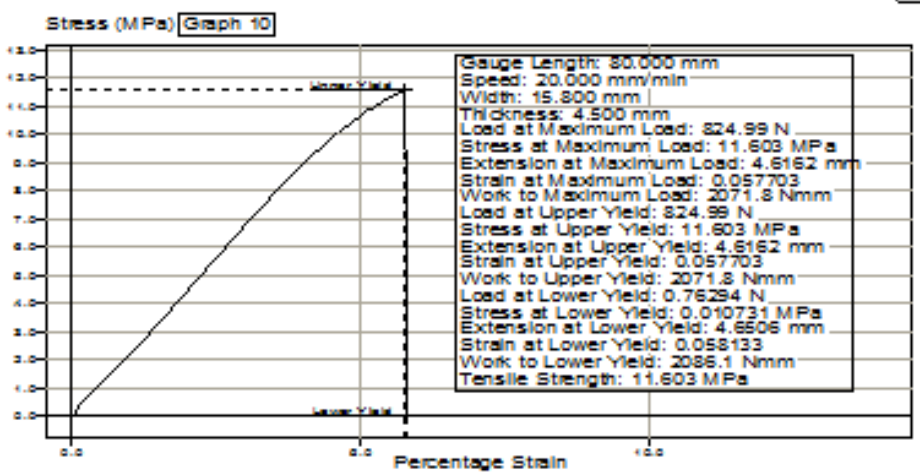

Fig. 8. Characteristic curve of a DS 65 resin sample 


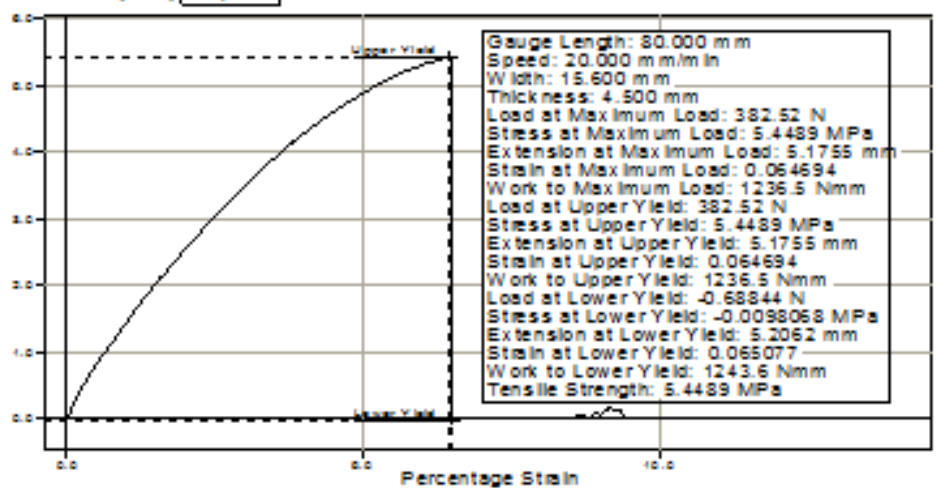

Fig. 9. Characteristic curve of a DS 75 resin sample

\begin{tabular}{|c|c|c|c|}
\hline Resin & $\begin{array}{c}\text { Tensile strength } \\
R_{m}[\mathrm{MPa}]\end{array}$ & $\begin{array}{c}\text { Elongation at break } \\
A[\%]\end{array}$ & $\begin{array}{c}\text { Modulus of elasticity } \\
E[\mathrm{MPa}]\end{array}$ \\
\hline DA 55 & $17.2-18.3$ & $1.87-2.18$ & $1550-1660$ \\
\hline DA 65 & $13.9-14.8$ & $2.68-3.04$ & $1140-1230$ \\
\hline DA 75 & $7.60-8.20$ & $4.16-4.92$ & $590-720$ \\
\hline DS 55 & $15.90-17.18$ & $4.73-5.34$ & $800-850$ \\
\hline DS 65 & $11.60-12.31$ & $5.45-5.77$ & $560-610$ \\
\hline DS 75 & $5.44-5.90$ & $6.46-7.30$ & $290-310$ \\
\hline Epoxy & $47.8-51.8$ & $1.52-1.81$ & $3230-3470$ \\
\hline
\end{tabular}

Table 2

EXPERIMENTAL RESULTS OF THE TENSILE TESTS
Table 2 shows the results obtained after tensile tests.

The highest values of the mechanical properties are obtained for the mixture with $55 \%$ Dammar (DA 55). In comparison with the epoxy resin, the tensile strength is $36 \%$ and the modulus of elasticity is $71 \%$. In the case of the mixture with 65\% Dammar (DA 65) the tensile strength is $29 \%$ and the modulus of elasticity is $71 \%$. In the case of the mixture with $75 \%$ Dammar the tensile strength is $16 \%$ and the modulus of elasticity is $29 \%$. An even more important decrease in properties appears in the case of the resin based on the mixture of Dammar and Sandarac. Comparing with the Dammar-based resin with the same proportion of epoxy resin, the tensile strength went down by $7 \%$ in the DS 55 resin, by $17 \%$ in the DS 65 resin and by around $28 \%$ in the DS 75. Moreover, the moduli of elasticity of the resins based on the mixture of Dammar and Sandarac are half in comparison with the resins based on Dammar only. The increase in the air volume in bio resin, at the same time with the increase in the volume proportion of Dammar or Dammar and Sandarac, may explain this decrease.

\section{Conclusions}

The use of natural resins for the manufacture of composite materials can be influenced by the resin properties and the capacity to create a synergetic effect together with the reinforcing materials. The analysis of the results we obtained show an important variation of the properties depending on the proportion between the natural and the synthetic resin.

Comparing the experimental results shows a significant modification of the mechanical properties when changing the proportion between epoxy resin and natural resins. We notice a decrease in the values of the tensile strength and the modulus of elasticity as the natural resin proportion is increased in the mixture. Although the mixtures with a higher amount of epoxy resin have superior mechanical properties, we cannot say that there is proportionality betw een tensile strength, or modulus of elasticity and the volume proportion of epoxy resin.

There are the modifications in the forms of the characteristic curves. If in the DA 55 and DS 55 resins, where the natural resin proportion is $55 \%$, the characteristic curve is almost linear, in the DA 75 and DS 75 resins, where the natural resin proportion is $75 \%$, there is an obvious nonlinearity of the characteristic curve which points out, in these cases, a plastic behaviour.

There are also modifications of the elongation at break, the latter increasing as the natural resin in the mixture is increased. The elongation at break is higher in the resins based on the mixture of Dammar and Sandarac than in the resins based on Dammar only. As a result, the Sandarac presence leads to an increase in the ductility of the obtained materials. This can be used to control the mechanical properties of the composite materials with a matrix of bio resins based on Dammar and Sandarac.

\section{References}

1.MALKAPURAM, R., KUMAR, V., YUVRAI, S.N., Recent development in natural fibre reinforced polypropylene composites, J. Reinf. Plast. Compos., 28, 2008, pp. 1169-1189

2.MOHANTY, A.K., MISRA, M., HINRICHSEN, G., Biofibers, biodegradable polymers and bio composites: an overview, Macromolecular Materials and Engineering, 276-277, 2000, pp. 1-24 3.SHOGREN, R.L., PETROVIC, Z., LIU, Z.S., ERHAN, S.Z., Biodegradation behavior of some vegetable oil-based polymers, J ournal of Polymers and the Environment, 12, 2004, pp. 173-178 4.UYAMA, H., KUWABARA, M., TSUJIMOTO, T., KOBAYASHI, S., Enzymatic synthesis and curing of biodegradable epoxide-containing polyesters from renewable resources, Biomacromolecules, 4, 2003, pp. 211-215

5.PRATI, S., SCIUTTO, G., MAZZEO, R., TORRI, C., FABBRI, D., Application of ATR-far-infrared spectroscopy to the analysis of natural resins, Anal. Bioanal. Chem., 399(9), 2011, pp. 3081-3091

6.SUPRAKAS, S.R., MOSTO, B., Biodegradable polymers and their layered silicate nanocomposites: in greening the 21st century materials world, Prog. Mater. Sci., 50, 2005, pp. 962-1079

7.ROMERO-NOGUERAM, J., MARTÍN-SÁNCHEZ, I., LÓPEZ-MIRAS, M.M., RAMOS-LOPEZ, J.M., BOLIVAR-GALIANO, F., Biodeterioration patterns found in Dammar resin used as art material, Electronic Journal of Biotechnology, 13(3), 2010, pp. 1-8

8.ZAKARIA, R., AHMAD, A.H., Adhesion and hardness evaluation of modified silicone-Dammar as natural coating materials, American Journal of Applied Sciences, 9(6), 2012, pp. 890-893

9.ZAKARIA, R., AHMAD, A.H., The performance of modified siliconeDammar resin in nanoindentation test, International Journal of Advanced Science and Technology, 42, 2012, pp. 33-44 
10.FAUZI, H, METSELAAR, H.S.C., MAHLIA, T.M.I., et al., Preparation and thermal characteristics of eutectic fatty acids/Shorea javanica composite for thermal energy storage. Appl. Therm. Eng., 100, 2016, pp. 62-67

11.HAMDANI, S., RIZAL, M., RIZA and T.M.I MAHLIA, Mechanical properties of concrete containing beeswax/dammar gum as phase change material for thermal energy storage, AIMS Energy, 6(3), 2018, pp. 521-529

12.NASIR, K.M., HALIM, N.A., TAJUDDIN, H.A., AROF, A.K., ABIDIN, Z.H.Z., The effect of PMMA on physical properties of Dammar for coating paint application, Pigment and Resin Technology, 42(2), 2013, pp. 137-145

13.NASTASESCU, V., MARZAVAN, S., A Model with Free Particles Used for Numerical Simulation of Charpy Impact Test of Plastic Materials, Mat. Plast., 53, no. 2, 2016, p. 222-226

14.AZEMARD, C., MENAGER, M., VIEILLESCAZES, C., On the tracks of sandarac, review and chemical analysis, Environ. Sci. Pollut. Res. 24(36), 2017, pp. 27746-27754

15.NAOKI, S., MASANORI, K., TAKASHI, K., SATO, K., Identification of the main constituents in sandarac resin, a natural gum base, Journal of the Food Hygienic Society of Japan, 47(2), 2006, pp. 76-90
16.KONONENKO, I., VIGUERIE, L., ROCHUT, S., WALTER, P., Qualitative and quantitative studies of chemical composition of sandarac resin by GC-MS, , Environ. Sci. Pollut. Res., 24, 2017, pp. 2160-2165

17.DRAGHICI, S., PETRESCU, H.A., HADAR, A., An obtaining the Young modulus from numerical analysis of composite material constituent, Mat. Plast., 55, no. 4, 2018, p. 712-717

18.PETHE, A.M., JOSHI, S.B., Physicomedical, Mechanical and film forming studies of novel biomaterial, International Journal of Pharmaceutical Sciences and Research, IJ PSR, 4(7), 2013, pp. 27612769

19.NURFAJ RIANI, L.W., GEA, S., THAMRIN, B.W., Mechanical properties of oil palm trunk by reactive compregnation method with Dammar resin, International J ournal of PharmTech Research, 8(1), 2015, pp. $74-79$

20.CIUCA, I., BOLCU, A., STANESCU, M.M., A study on some mechanical properties of bio-composite materials with a Dammar based matrix, Environmental Engineering and Management Journal, 16(12), 2017, pp. 2851-2856

21.STANESCU, M.M., Study regarding the mechanical behaviour of Dammar based composite materials, reinforced with natural fiber fabrics, Mat. Plast., 52, no. 4, 2015, p. 596-600

Manuscript received: 21.01 .2019 